\title{
Originarii et adscripticii: análisis de su diferente condición jurídica, administrativa y fiscal
}

\author{
MARÍA LUISA LÓPEZ-HugUeT ${ }^{1}$
}

\section{RESUMEN}

A mitad del siglo IV los coloni originarii son vinculados perpetua y hereditariamente al suelo cultivado, favoreciendo que la base imponible de la capitación se establezca en proporción a las unidades de tierra y que la responsabilidad fiscal se traslade a su propietario. A partir del siglo $\mathrm{V}$, en la parte occidental, el ligamen al suelo queda sujeto a las reglas liberatorias de la prescripción. En la parte oriental, comienza a configurarse la condición adscripticia que ultima Justiniano, estableciendo su carácter hereditario, imprescriptible, su incapacidad patrimonial, una severa regulación matrimonial y estrictos requisitos para decretar la validez contractual de la vinculación como adscripticius de una persona libre.

Palabras clave: Derecho romano, Derecho administrativo, Capacidad de obrar, Estatuto jurídico, Derecho fiscal, Domicilio legal, Colonos.

1 Doctora en Derecho por la Universidad Internacional de La Rioja, profesora agregada de Derecho Romano y vicedecana de Derecho de la Universidad Internacional de La Rioja (UNIR), Logroño, La Rioja, España. Autora de múltiples publicaciones científicas. Ha participado en diversos proyectos de investigación y congresos. En la actualidad es miembro del Gdi "Justicia, Derecho y Globalización" en el marco del III Plan Propio de Investigación de UNIR-Research (bienio 2015-2017) y compagina su actividad académica con la asesoría jurídica privada y la función de juez de paz en el municipio de Arnedo, España. Su investigación se centra en aspectos de derecho administrativo romano, como miembro de la Escuela que dirige el Profesor Dr. Antonio Fernández de Buján, especialmente, en la regulación jurídica del domicilio, la ciudadanía y los munera locales. Correo-e: marialuisa.lopez@unir.net Fecha de recepción: 2 de julio de 2016. Fecha de modificación: 30 de agosto de 2016. Fecha de aceptación: 15 de septiembre de 2016. Para citar el artículo: Lopéz-Huguet, M. L. "Originarii et adscripticii: análisis de su diferente condición jurídica, administrativa y fiscal", Revista digital de Derecho Administrativo, n. ${ }^{\circ} 16$, segundo semestre, Universidad Externado de Colombia, 2016, pp. 193-220. DOI: http:// dx.doi.org/10.18601/21452946.n16.10. 


\title{
Originarii et Adscripticii: Analysis of the Different Legal, Administrative and Fiscal Condition
}

\begin{abstract}
In the mid- $4^{\text {th }}$ century the originarii coloni were perpetually and hereditarily tied to the cultivated land, thus promoting the practice of having the taxable amount of capitation be established in proportion to the land units and moving the fiscal responsibility to its owner. Starting the in the $5^{\text {th }}$ century, in the West part of the Roman Empire, the act of being tied to the land became subject to the discharged rules of prescription. In the East part of the Roman Empire, the concept of adscripticia condicio begins at the end of Justinian period, establishing its hereditary and indefeasible character, its financial inability, a rigid marital regulation and strict requirements to declare the validity of a contract which links a free person as adscripticius.
\end{abstract}

Keywords: Roman Law, Administrative Law, Legal Capacity, Legal Status, Tax Law, Legal Domicile, coloni.

\section{INTRODUCCIÓN}

El profesor Antonio Fernández de Buján, máximo exponente en el estudio del derecho administrativo romano, afirma que, en época posclásica, el colonus "estaba vinculado perpetua y colectivamente a la tierra que trabajaba" y su dependencia de potestad ajena, permitía clasificarlo entre los supuestos de libertad formal, entendidos genéricamente como aquellos en los "que una persona se encuentra en una situación de sometimiento o vinculación, respecto de otra, de tal naturaleza, que si bien conserva formalmente la libertad, se aproxima en su posición jurídica a la propia de la persona sometida a esclavitud, tanto en el ámbito de su autonomía personal como patrimonial"2. No obstante, como señalan Fatás y Marco, el término colonus careció en las fuentes romanas de un significado único y válido para todas las épocas, siendo utilizado para designar realidades diversas a través de una evolución semántica que se desarrolla a lo largo de las distintas etapas del derecho romano ${ }^{3}$.

2 Antonio Fernández de Buján, Derecho privado romano, Madrid: Iustel, 8. ${ }^{a}$ ed., 2015, p. 184.

3 Guillermo Fatás y Francisco Marco, "Consideraciones sobre el colonato", Memorias de Historia Antigua, n. ${ }^{\circ} 2,1978$, pp. 187 ss. 
Etimológicamente, colonus procede de colere y designa comúnmente "qui terram colit", es decir, al cultivador de la tierra ${ }^{4}$. Es un significado propio de época arcaica en la que la escasa esclavitud condujo a la equiparación de los conceptos de cliente y colono, en cuanto cultivadores de la tierra que pertenecía en propiedad colectiva a la gens ${ }^{5}$. Partiendo de este primitivo significado, la política expansionista romana determina que, sobre todo a partir del siglo III a.C., el término colonus mute de significado y pase a designar al pleno ciudadano de una colonia romana o latina. En efecto, como tuvimos oportunidad de exponer en otra sede, este empleo del término es abundante en las fuentes literarias y epigráficas a partir de la época republicana, en las que junto a los ciudadanos de pleno derecho -que en función del estado de la ciudad son designados como cives, municipes o coloni-se menciona también a los residentes estables o incolae, diferenciándolos o equiparándolos en relación con diversos aspectos de la vida local ${ }^{6}$.

Avanzando en el tiempo, las fuentes literarias y jurídicas de los primeros siglos del Imperio permiten constatar una nueva variación semántica puesto que en ellas se emplea el término colonus para designar una clase de arrendatario (conductor): el conductor praedii rustici, por oposición al inquilinus o conductor praedii urbani ${ }^{7}$. Por tanto, colono era el arrendatario que cultivaba la tierra a cambio de una prestación en dinero o en frutos: colonus partiarius ${ }^{8}$.

4 R. Brosz, "Les changementes sémantiques du mot "colonus" dans le sources du droit Romain", Annales Universitatis Scientarum Budapestinensis, 1959, 39 ss.; A. ERNOUT, A. MEILlET, Dictionnaire étymologique de la langue latine. Histoire des mots, París, 4. ${ }^{a}$ ed., 1967, p. 132, su voz "colonus".

5 Francesco De Martino, "Coloni in Italia", en Labeo, I, 1995, pp. 35 ss.; María Teresa Marín García y José Antonio Martínez Vela, "Claves para el estudio del colonato romano", III Congreso Iberoamericano de Derecho Romano, León: Universidad de León, 1998, p. 237; GIUSEPPE GiLIBERTI, Servi della terra. Richerche per una storia del colonato, Torino: Giappichelli, 1998, p. 28.

6 Así, entre otras, Tito Livio, Ab urbe condita, 34.425-6; Lex Ursonensis, cap. 5.2; cap. 95; cap. 98; cap. 103; y cap. 126; CIL. I. 585.66; C.I.L. V. 376; C.I.L. XIV. $2978=$ I.L.S. 5672. MARÍA LUISA LÓPEZ HuGuET, Régimen jurídico del domicilio en derecho romano, Madrid: Dykinson, 2008, pp. 371 y 413 ss.

7 Cicerón, pro Caecina, 94; Varrón, De re rustica, 1.2.17; Séneca, De beneficiis, 7.5.2; Columela, De re rustica, 1.7.1, D. 19.2.9\$3; D. 19.2.24§1; D. 43.16.20. GuSTAVE HumberT, s.v. "colonus", en D.S., 1.2, París, 1877, pp.1322; ARNOLD H.M. JonES, "El colonato romano", Estudios sobre Historia Antigua, Madrid, 1981, pp. 315-316, FATÁS y MARCO, "Consideraciones...", cit., 188 ss.; FrANCESCO De MARTINO, "Il colonato fra economia e diritto", AA.VV., Storia di Roma (dirs. A. Momigliano y A. SCHIAVONE), Torino, III.1, 1989, pp. 803 ss.

8 D. 19.2.25 § 6. Denis Fustel De Coulanges, Le colonat romain, París: Arno Press, 1884, 13 ss.; P.W DE NEEVE, "Colon et colon partiaire", Mnemosyne, 37, 1984, pp. 125-142, GILIBERTI, Servi..., cit., 38 ss.; PASQUALE ROSAFIO, "Coloni imperiali e coloni privati nella legislazione del quarto secolo", Atti dell'Accademia Romanistica Costantiniana. X Convegno Internazionale in onore de Arnaldo Biscardi, Perugia, 1991, 452 ss.; Francisco CuEnA Boy, "Yanaconazgo y derecho romano: ¿una conjunción extravagante?", REHJ, 28, 2006, 6. 
Pero, como constata Brosz, junto a este significado genérico de conductor de un contrato típico de arrendamiento, en otras fuentes se utiliza el término con diferentes connotaciones. Así, en la lex colonis fundi Villae Magnae data ad exemplum legis Mancianae, que regula las relaciones dentro de un fundo estatal, con conductor se indica al arrendatario que no cultiva la tierra personalmente, mientras que con colonus se alude al sujeto que en realidad cultiva la tierra subordinado al conductor ${ }^{9}$. Y también interesante en esta variedad de matices es un pasaje de Escévola en el que se distinguen dos categorías de colonos: los coloni extranei o arrendatarios libres y los coloni fide dominica o esclavos arrendatarios de su señor ${ }^{10}$.

En el empleo del término colonus con estas nuevas connotaciones se aprecia una pausada evolución hacia su significado de sujeto de condición casi servil, aunque las fuentes de la época conservadas todavía conciban al colono como un hombre libre que, si bien puede tener tierras propias, cultiva una parcela ajena en régimen de arriendo o subarriendo durante el plazo de explotación convenido y con capacidad jurídica de defensa judicial ${ }^{11}$.

En realidad, sólo a partir del siglo IV, cuando el contrato de arrendamiento libre es modificado y sustituido por otros sistemas perpetuos de producción agrícola, la relación contractual se transformará en una relación de dependencia entre el colono y la parcela de tierra que cultivaba, impulsada, según De Martino, por la necesidad de asegurar la explotación de las tierras, evitando su abandono, y el nuevo sistema impositivo, basado en las unidades de propiedad (iuga) y en la fuerza de trabajo (capita), lo que provocó que los colonos fuesen vinculados perpetua y hereditariamente al suelo que trabajaban ${ }^{12}$.

En el mismo sentido se pronuncia BRAVO, para quien "el colono 'libre' se transformó en campesino dependiente no tanto por 'pertenecer a' sino por 'estar obligado a' bajo las condiciones estipuladas en el arriendo o en aplicación de las normas que regulaban las nuevas formas de cesión del suelo cultivado o abandonado (agri deserti) puestas en práctica por la administración"13.

Ahora bien, ello no significa que el agricultor libre vinculado por un contrato tipo de arrendamiento desapareciera, ni que la configuración del colono como un arrendatario perpetuo y hereditario fuese homogénea, encerrando

9 C.I.L. VIII. 25902 -Henchir-Mettich-; D. 50.6.6\$10-11; D. 19.2 .49 pr.; C.I. 5.41.1; C.I. 5.62.8. Brosz, "Les changements...", cit., 41; JERZY KOLENDO, Le colonat en Afrique sous le Haut-Empire, París, 1976, 10 ss.; ARNALDO MARCONE, Il colonato tardoantico nella storiagrafia moderna, Como: Edizioni New Press, 1988, 27 ss.

10 D. 33.7.20 $\$$ 1. Brosz, "Les changements...", cit., 41. En el mismo sentido, con anterioridad, HuMBERT, s. v. "colonus", cit., 1322.

11 Gayo, Institutae, 4.153. Marín García-Martínez Vela, "Claves...", cit., 237-238.

12 C. Theod. 5.17.1; C.I. 11.47-48-.7; C.I. 11.50-51-.1. DE MARTINO, "Il colonato...", cit., 798 y 820 .

13 G. BRAVO, El colonato bajoimperial, Madrid: Akal, 1991, 11 
la diversidad terminológica de las fuentes una diversidad sustancial en lo que afecta al vínculo de relación, de tal forma que la unificación bajo el apelativo "colonus" responde más a su valoración fiscal que a la situación particular ${ }^{14}$.

En este sentido, la doctrina ha diferenciado cinco clases de colonos, aunque con discrepancias en el punto de vista del análisis y en la interpretación de su régimen jurídico: originarii, adscripticii, inquilini, tributarii y servi ${ }^{15}$.

En todo caso, aunque la heterogeneidad jurídica existente en el campesinado dependiente resulta innegable, se puede afirmar con BRAVO que estuvo caracterizado por dos rasgos esenciales: uno de orden fiscal, en cuanto grupo sujeto al impuesto de la tierra que cultivaba estuviera o no adscrito a ella; y otro de orden social, en cuanto clase de bumilliores que sufrió una progresiva degradación socioeconómica con la consiguiente pérdida de derechos ${ }^{16}$.

Partiendo de estas dos premisas, en el presente trabajo nos centraremos en el análisis de la distinta situación jurídica, administrativa y fiscal de los colonos originarios de la parte occidental y de los colonos adscripticios de la parte oriental del Imperio.

\section{COLONI ORIGINARII}

\section{I.1. LA VINCULACIÓN DEL COLONO A SU ORIGO TRAS LA REFORMA FISCAL DE DiOCLECIANO}

En este proceso de transformación de agricultor libre a campesino dependiente que experimenta el colono en el Bajo Imperio, la mayor parte de los autores coinciden en afirmar que confluyeron razones de orden socio-productivo ${ }^{17}$,

14 C. Grey, "Contextualizing Colonatus: The Origo of the Late Roman Empire", Journal Roman Studies, n. ${ }^{\circ}$ 97, 2007, 155-175.

15 Para M. RostovtZEFF, s.v. "Kolonat", Handwörterbucb der Staatswissenschaften, V, 1910, 919 920, la diferente terminología se refiere a un diferente aspecto, local o jurídico, de los colonos: inquilini y colonus (y también casarii) presuponen el punto de vista del propietario; tributarius y adscripticius, aquel de la administración fiscal; originalis y originarius el principio del origo; mientras plebs y populus plebeius se refieren a la condición social del colono. Por su parte, PAUl Collinet, "Le colonat dans l'Empire Romain", Recueil de la Société Jean Bodin, Bruxelles, 1937, 94 ss., distinguía, en función de su origen, entre "colonos imperiales y eclesiásticos", cuyo régimen fluctuaba según el tipo de fundo al que estuvieran adscritos, y "colonos privados", en los que encuadra a las cinco clases mencionadas. Esta clasificación de Collinet es seguida por M. T. Marín García y José Antonio Martínez Vela, "Claves...", cit., 239.

16 G. Bravo, El colonato..., cit., 11 ss. Una postura más acusada en este sentido sostiene C. GREY, "Contextualizing...", cit., 174-175, para quien elaborar una teoría general sobre el colonato es un quimera.

17 Así, JONES, "El colonato romano", cit., 322-323. 
de índole fiscal ${ }^{18}$ o de ambas ${ }^{19}$, en la medida en que era necesario asegurar la explotación de las tierras, evitando su abandono, en aras de garantizar los aprovisionamientos alimentarios y racionalizar el cobro de los impuestos, transformándose el contrato de arrendamiento libre por plazo determinado en una relación de dependencia entre el colono y la parcela de tierra que cultivaba.

Los grandes latifundistas, afirma BRAVO, necesitaban garantizar la estabilidad de sus fuerzas productivas en las parcelas dispersas en que se dividía su amplio dominio, una necesidad que se hará más acusada en las grandes explotaciones, al sustituirse la mano de obra esclava por el trabajo libre, pero también en las medianas y pequeñas explotaciones en las que, bajo la organización descentralizada de la villa, la producción esclavista subsistió en alternancia con la explotación indirecta ${ }^{20}$. Asimismo, los agricultores, de muy diversa condición, también estaban interesados en asegurar su raigambre en las parcelas que trabajaban. Algunos eran pequeños campesinos-propietarios con escasos excedentes comerciales que obtenían ingresos suplementarios con los que aliviar su complicada situación económica a través del cultivo de tierras ajenas. Otros eran arrendatarios (ingenuos o libertos) sin tierras o proletarios urbanos contratados como asalariados en calidad de tenentes, a los que su permanencia en las parcelas garantizaba su medio de subsistencia. Todo ello, sin olvidar a los servus quasi coloni y su posible conversión en libertos ${ }^{21}$.

Sobre este mosaico de relaciones socio-productivas, continúa el autor, el Estado impulsó la implantación del colonato para explotar las tierras no cultivadas (loca inculta) o abandonadas (agri deserti) y para garantizar los ingresos fiscales, de manera que el sistema colonario acabó relegando a las otras formas de producción (locatio-conductio, ius perpetuum, enfiteusis o epibolé) y las distintas clases de campesinado fueron asemejándose a la condición formal de colono, pasando a convertirse, paulatinamente, en campesinado dependiente de la tierra, sin que ello generase un status jurídico unitario, sino que cada cual conservaba su estado primigenio en tanto no fuera integrado entre

18 Entre otros, JEAN-MiCHEL CARRIÉ, "Le colonat du Bas-Empire: un myhte historiographique?", Opus, I.2, 1982, 351 ss.; GreY, "Contextualizing...", cit., 155 ss.; Bravo, El colonato..., cit., 26; MARGARITA FUENTESECA, "El colonus y el impuesto territorial", R.I.D.R.O.M., n. ${ }^{\circ}$ 3, 2009 , p. 76.

19 En este sentido, Paul Collinet, "Le colonat...", cit., 94 ss.; De Martino, F., "Schiavi e coloni tra antichità e medioevo", Uomini e terre in Occidente tra tardo antico e medioevo, Napoli, 1988, 93 ss.; Marín García-Martínez Vela, "Claves...", cit., 246-247; Giliberti, Servi..., cit., 18 y 81 .

20 GonZalo Bravo, "El estatuto sociopolítico del colono en la génesis de la sociedad bajoimperial", Memorias de Historia Antigua, n. ${ }^{\circ}$ 2, 1978, 63 ss.; idem, El colonato..., cit., págs. 19 ss.; GILIBERTI, Servi..., cit., 21 ss. y 77 ss.

21 BRAVO, "El estatuto...", cit., 63 ss.; idem, El colonato..., cit., 8 y 10. 
los adscripticii o estableciera una relación de patrocinio con el propietario de las tierras que cultivaba ${ }^{22}$.

Y en este contexto, algunos autores ubican el origen de la regulación legal del colonato privado en la reforma fiscal de Diocleciano, al extender a todo el Imperio el tributum capitis y unificar el impuesto territorial y el personal (ingatio-capitatio) remitiendo la responsabilidad fiscal, no a las fortunas personales valoradas en dinero, sino a los principales recursos de cada dominio censado, a sus tierras (iugatio), animales y hombres (capitatio), exigiendo la recaudación impositiva sobre la base de las declaraciones censales, lo que supuso el ligamen formal del colono al fundo en que había sido censado y la restricción de su libertad de movimientos que será sancionada legalmente por los emperadores sucesivos ${ }^{23}$.

En apoyo de esta teoría, señalan una constitución del año 332 que el emperador Constantino dirige a los provinciales en la que dispone que cualquier persona que se encontrase un colono perteneciente a otra debía devolverlo a su lugar de origen y estaba sujeta a los impuestos por el tiempo que lo hubiera tenido. Se autorizaba además a los propietarios a retener por la fuerza a los colonos que planeasen huir, e incluso a encadenarlos para coaccionarles a cumplir sus obligaciones de campesinos libres como si fueran esclavos ${ }^{24}$.

Para estos autores, la disposición ya presumiría la existencia del colonato, siendo simplemente la primera manifestación concreta que establece la vinculación del colono a la tierra de la que se tiene constancia y el procedimiento al cual se remonta la sumisión de los colonos adscripticios a la potestad del poseedor privado 25 .

No obstante, como indica Fuenteseca, no queda clara cuál fue la reforma fiscal de Diocleciano, aunque sí se infiere un cambio en la confección del censo que se tomaba como base para la exacción de la capitatio. Con el tributum capitis se gravaba el patrimonio del civis romano constituido por todos sus bienes inscritos en el censo. El pago de este impuesto estaba unido a la condición de ciudadano romano pero, tras la concesión de la ciudadanía por Caracalla, este impuesto se pagaba por el possessor ${ }^{26}$.

22 BRAVO, El colonato..., cit., 26.

23 JONES, A.H.M., "Capitatio y iugatio", J.R.S., XLVII, 1957, 88-94; íd., "El colonato romano", cit., 330; JEAN-Michel CARRIÉ, "Un roman des origines: Les généalogies du colonat du Bas-Empire", Opus, II.1, 1983, 215; Bravo, "El estatuto...", cit., 64 ss.; idem, El colonato..., cit., 33 y 39 .

25 JONES, "El colonato romano", cit., 316; MARCONE, Il colonato..., cit., 13; GILIBERTI, Servi..., cit., 83 ss. Vid., CH. SaumaGnE, "Du role de "l'origo" et du "census" dans la formation du colonat romain", Bizantion, 12, 1937, 508 y 536, para quien la norma está interpolada. 
Y, como señala Goffart, si bien es claro que el objetivo primordial de esta ley de Constantino era evitar la evasión fiscal de los colonos huidos y ocultados, tratando de impedir que abandonasen las tierras que normalmente cultivaban, se debe observar que la norma los vincula a su origo en cuanto contribuyentes de la capitatio, pero que no identifica tal origo con el fundo cultivado sino con el lugar de origen o procedencia, por lo que no podemos afirmar que prescribiese el ligamen del colono al suelo que cultivaba, algo que sólo se producirá más adelante. Hasta ese momento, como la capacidad contributiva de los colonos requería mantener sus rendimientos de explotación en unos niveles de producción idóneos para poder cumplir con sus cargas impositivas, los emperadores sucesivos adoptarán una serie de medidas tendentes a consolidar su estabilidad -y la de los esclavos- como fuerza productiva en los fundos $y$, con ello, asegurar su suficiencia contributiva ${ }^{27}$.

\section{2 DE LA SUJECIÓN DETERMINADA POR EL ORIGO AL VÍNCULO ADMINISTRATIVO CON LA TIERRA A PARTIR DE LA SEGUNDA MITAD DEL SIGLO IV}

En esa política dirigida a garantizar la estabilidad productiva y contributiva de los colonos, Jones señala una constitución del emperador Valente del año 364 en la que se ordena que fueran restituidos, a los fundos y posesiones imperiales, los esclavos y colonos, con sus hijos y nietos, que clandestinamente hubieran pasado a realizar diversos oficios, aunque hubiesen entrado en el ejército o en el cuerpo de protectores ${ }^{28}$.

Esta disposición es refrendada un año después por los emperadores Valentiniano y Valente, recordando que numerosas veces se había establecido que los esclavos y libertos, así como los colonos de la res privata junto con sus descendientes que se hubiesen marchado de las posesiones para ingresar en el ejército, fueran devueltos al patrimonio imperial y despojados del cíngulo fraudulentamente obtenido, si acaso hubieran ocupado alguna dignidad, quedando suprimidas las reglas de la prescripción temporal ${ }^{29}$.

Ambas constituciones, interpreta Rosafio, confirman el carácter hereditario de los colonos originales imperiales, que será reforzado mediante diversos procedimientos relativos a las uniones de las colonas de la casa imperial con hombres que no tenían ningún vínculo con ella ${ }^{30}$. El autor diferencia la vincu-

27 W. GOFFART, Caput and Colonate. Towards a bistory of Late Roman Taxation, Toronto, 1974, 70 ss.

28 C.I. 11.67-68-.3. JONES, "El colonato romano", cit., 316; PASQUale RosafiO, Studi sul colonato, Bari: Edipuglia, 2002, 177 ss. Vid. M. ANTONIO DE DOMINICIS, "I coloni adscripticii nella legislazione di Giustiniano", Studi Betti, III, Milano, 1962, 93, quien atribuye la constitución a Constantino.

29 C.I. 7.38.1. JONES, "El colonato romano", cit., 316, RoSAFIO, Studi..., cit., 179-180.

30 C.I. 6.4.2; C.I. 11.67-68-.4; C.I. 10.32.29. Pasquale RosafIO, "Coloni...", cit, 457 ss.; idem, Studi..., cit., 136 ss., 177 ss. y 206 ss. 
lación de los colonos imperiales -anterior a Diocleciano y para liberarles de los munera civilia- y la vinculación de los colonos privados, por motivos fiscales, a partir de Constantino. Pero, en realidad, como indica De Martino, las fuentes no permiten avalar esta opinión sino su surgimiento coetáneo ${ }^{31}$.

Por lo que se refiere a los colonos privados, la vinculación al lugar de procedencia (origo) se aprecia en una constitución de Valentiniano y Valente del año 366 dirigida a los gobernadores provinciales de la Galia para que obligasen a los colonos e inquilinos a retornar a los hogares donde estaban registrados, habían nacido y crecido, sin diferencia de sexo, cargo o condición ${ }^{32}$.

La constitución manifiesta la tendencia a delimitar una regulación del colonato de ámbito regional, y su último inciso "educati natique" podría ser una referencia al origo, análogamente a lo que había dicho Constantino en el año $332^{[33]}$. En todo caso, la relación entre la inscripción al censo y el pago del tributo, que no se aprecia en esta constitución, se hace evidente en otra norma de los mismos emperadores, en virtud de la cual los colonos sin tierras, inscritos en el censo a cargo de sus propietarios, son tomados en consideración en cuanto originales, originarii del fundo que cultivan, de modo análogo a los coloni originales que trabajaban en los dominios imperiales ${ }^{34} ; \mathrm{y}$ aunque el propietario sólo era responsable del pago de la capitatio en caso de fuga ${ }^{35}$, resultaba su regular perceptor directamente o a través de sus actores. En cambio, el colono que tenía alguna propiedad de tierras, por pequeña que fuera, era inscrito en el censo de manera separada y obligado también al pago de la capitatio del fundo arrendado ${ }^{36}$.

Por tanto, mientras para los colonos no propietarios se identifica el origo con el lugar de las tierras que cultivan, los campesinos propietarios eran registrados en sus aldeas y podían ser vinculados a ellas y no a la tierra que tra-

31 De Martino, "Il colonato...", cit., 798; Giliberti, Servi..., cit., 82 ss. y 101 ss.

32 C.I. 11.47-48-.6 (int.).

33 Pasquale Rosafio, "Coloni...", cit., 458-459; idem, Studi..., cit., 182; Bravo, El colonato..., cit., 17; GiliberTi, Servi..., cit., 100 n. 110. Vid. Saumagne, "Du role...", cit., 528-529, para quien no será hasta comienzos del siglo IV cuando el origo se comunique por nacimiento a los colonos de los fundos privados (C.I. 11.47-48-.13; C. Theod. 5.18.1).

34 C. Theod. 11.1.14=C.I. 11.47-48-.4. Vid. C.I. 11.67-68-.1. GILIBERTI, Servi..., cit., $101 \mathrm{n}$. 114; RosafiO, Studi..., cit., pp. 144 ss. y 177 ss.

35 Ya con anterioridad (año 361) se había responsabilizado a los senadores por las tasas de sus colonos huidos. C. Theod. 11.1.7. G. Bravo, El colonato..., cit., 38-39; GiliberTi, Servi..., cit., 99 .

36 DIETHER EIBACH, Untersucbungen zu spätantiken kolonat der kaiserlichen Gesetzgebung unter besonderer Berücksicbtigung der Terminologie, Cologne: Diss. Köln, 1977, p. 24, considera esta constitución como una etapa esencial en el desarrollo del colonato dependiente; GILIBERTI, Servi..., cit., 99; Pasquale Rosafio, Studi..., cit., 183-184; Grey, "Contextualizing...", cit., 166 ss.; FUENTESECA, "El colonus...", cit., pp. 76-77. 
bajaban ni al propietario de la misma ${ }^{37}$. Eran, como indica GILIBERTI, "colonos en el sentido tradicional del término, obligados sólo a responder al locator de las ordinarias obligaciones contractuales" ${ }^{\prime \prime 28}$.

Para algunos autores esta constitución marca el origen del colonato al instaurar la autopragia, esto es, el derecho otorgado por el Estado a los propietarios latifundistas para recaudar los impuestos debidos por los trabajadores agrícolas de sus tierras ${ }^{39}$.

A nuestro juicio, esta norma señala el punto de inflexión en virtud del cual los colonos pasarán de estar sujetos de manera perpetua y hereditaria, no a su origen en cuanto tributarios, sino directamente al suelo cultivado en su condición de colonos, gracias a un cambio en el sistema impositivo, en virtud del cual la base imponible de la capitación se establece cada vez más en proporción a las unidades de tierra y la responsabilidad fiscal se traslada al propietario de las mismas.

No en vano, sólo dos años después, como señala JONES, los mismos emperadores dictan una de las dos únicas leyes que dispusieron la devolución de los campesinos propietarios a su lugar de procedencia, al establecer que si alguien solicitaba la concesión de un hombre aduciendo que era vagabundo o esclavo sin dueño, se debía proceder a una investigación, y si se demostraba que el solicitante había utilizado este procedimiento para esconder un colono ajeno, era obligado a devolverlo y a pagar los tributos que este debía, siendo conminada la pena prevista por la ley si el escondido era un esclavo. En cambio, para el que demostrase ser de condición plebeya o libre se decretaba la liberación de toda molestia y la restitución a su lugar de procedencia ${ }^{40}$.

Sin embargo, numerosas son las constituciones que pretenden garantizar la continuidad de los colonos sin tierras y evitar su fuga de los campos que trabajan, llegándose incluso a prohibir su venta por separado. Paradigmática en este sentido es una constitución del año 371 en la que Valentiniano, Valente y Graciano, retomando medidas anteriores ${ }^{41}$, restringen la capacidad de los

38 GiLIBERTI, Servi..., cit., p. 99

39 JEAn GaSCOU, "Les grands domaines, la cité et l'État en Égypte byzantine", Travaux et Mémoires Byz., 9, 1985, 1-90. Vid. Boudewijn SIRKS, "Reconsidering the Roman Colonate", ZSS,

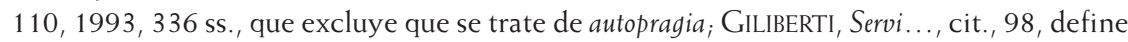
la autopragia como la posibilidad de pagar directamente los impuestos al presidente de la provincia sin mediación de los órganos ciudadanos, y afirma que esta posibilidad fue ya concedida en el año 383 en la diócesis Póntica (C. Theod. 11.7.12) pero no comparte la opinión de un reconocimiento automático de la autopragia para todos los fundos de una cierta extensión y señala cómo Honorio y Teodosio, en el año 409 (C. Theod. 11.22.4), condenan la praxis de eludir la intervención de los curiales.

40 C. Theod. 10.12.2; C. Theod. 11.24.6. JONES, "El colonato romano", cit., 323.

41 BRAVO, El colonato..., cit., 42 y 46, señala como antecedentes: C. Theod. 11.3.2 (a. 327); C. Theod. 11.22.1 (a. 346); C. Theod, 13.10.3=C.I. 11.47-48-.2 (a. 357). PAsQUale RosafiO, 
propietarios para trasvasar colonos y esclavos de un fundo a otro dentro de su propio dominio, a la vez que prohíben al propietario enajenar la tierra sin transferir con ella a los colonos (originarii) y a los esclavos agrícolas censados, debiendo todos permanecer en el fundo; en caso contrario, el adquirente o sus herederos podrían reclamarlos al vendedor o a sus descendientes sin que sea obstáculo la praescriptio longi temporis ${ }^{42}$.

En ese mismo año, como recoge BRAVO, otra constitución de igual autoría que la anterior desarrolla la disposición emanada por Constantino en el año 332 , regulando los supuestos en que los colonos fugitivos se instalasen al servicio de un nuevo propietario y sancionando la culpabilidad o inocencia de los propietarios encubridores, en función de las condiciones en que hubieran acogido a los colonos huidos: si ignoraban que los colonos eran prófugos y los habían contratado legalmente creyendo que se trataba de campesinos libres, se establecía su inocencia obligando a los propios colonos a satisfacer sus deudas fiscales; por el contrario, si los propietarios conocían su condición de fugitivos y no obstante los habían utilizado para su propio beneficio, se decretaba su culpabilidad y se les compelía a ingresar en las arcas públicas los emolumentos tributarios debidos por los huidos, así como a indemnizar a los antiguos propietarios por las jornadas no trabajadas en sus respectivas explotaciones $^{43}$.

Studi..., cit., 166, 188 y 209, indica que esta medida fue perfeccionada por Honorio (C.I. 11.47-48-.13). Sobre C. Theod, 13.10.3, recientemente Francisco CuEnA Boy, "Causa originis': Normas de procedimiento sobre la reclamación de colonos o curiales evadidos de su condición", en REHJ, n. ${ }^{\circ}$ XXXIV, Valparaíso, 2012, 55-89.

42 C.I. 11.47-48-.7. SAUmagne, "Du role...", cit., 539, la data en el año 376; JONES, "El colonato romano", cit., 324, indica que esta medida fue revocada por el rey Teodorico en Italia (Edictum Theodorici, 142), BraVo, El colonato..., cit., 42 y 47; GILIBERTI, Servi..., cit., 88 , estima que la proporción que debía mantenerse entre la parte del fundo cedida y los colonos efectivamente empleados en ella probablemente asumiera como base la pequeña factoría colonial, ROSAFIO, Studi..., cit., 188-189, señala que en esta constitución se emplea por primera vez el término originarii como sustantivo que debe interpretarse como sinónimo de coloni originales y, de acuerdo con su redacción, analiza la disposición desde el punto de vista del adquirente: este debía comprar todo o parte del fundo con tantos esclavos y originarii como tuviera el anterior propietario o poseedor, siendo sancionado el adquirente transgresor con la pérdida del precio correspondiente y pudiendo el vendedor recuperar los esclavos y su prole, derecho que pasa a sus herederos que podrán dirigirse contra el comprador o sus descendientes, quedando excluida la prescripción de largo tiempo porque es poseedor de mala fe quien compra una cosa contra las prohibiciones de las leyes. Ya anteriormente, en este sentido, HUMBERT, s.v. "colonus", cit., 1323 ss.

43 C.I. 11.47-48-.8. BRAVO, El colonato..., cit., 42-43; De MARTINO, "Il colonato...", cit., 815 n. 134, observa en esta constitución un reenvío a las costumbres del lugar del fundo en relación con los obligaciones previstas para el cultivo y el pago del canon; GILIBERTI, Servi..., cit., 86-87; ROSAFIO, Studi..., cit., 190-191, para quien los emolumenta tributaria se corresponderían a la capitatio constantiniana, Vid. SAUMAGnE, "Du role...", cit., 516-517, que la data en torno al año 374 . 
La constitución nos suministra asimismo información sobre el tipo de relación que se podía entablar entre el colono y el propietario. Como indica SAUMAGNE, si no ocultaba su condición de fugitivo, podía cultivar el campo y entregar los frutos al propietario o podía realizar trabajos que incrementasen la superficie cultivada del fundo sin recibir compensación alguna. Por el contrario, si se presentaba como un colono libre, podía disponer del terreno para cultivar, entregando una parte de los frutos al nuevo propietario y conservando el resto para sí, o bien podía realizar labores tendentes a innovar el fundo a cambio de la merced acordada ${ }^{44}$.

En esta sede, en torno a los mismos años, otra ley de Valentiniano, Valente y Graciano, citada por Marcone, permite dibujar el boceto de una hacienda agrícola, por medio del detallado inventario que deben hacer las autoridades locales con motivo de la confiscación para la res privata de los bienes de un proscrito: cantidad de tierra, tipos de cultivo, número de vides y olivos, extensión de tierra arada, de pastos, de bosques, la ubicación, los edificios, los objetos de valor, el número de esclavos rústicos y urbanos, así como su función, el número de casarii y de colonos, de bueyes, las piaras y clases de ganado menor y mayor, la cantidad de oro y plata, de vestidos y joyas, con indicación del tipo y peso, y todo lo que era conservado en los armarios ${ }^{45}$.

Los colonos, por tanto, junto con los casarii, son considerados parte integrante de la hacienda descrita con todo su instrumentum pero netamente distintos de los mancipia ${ }^{46}$. Su condición no debía por eso ser jurídicamente inferior pero se constata, a juicio de Rosafio, "una clara confirmación del vínculo a la hacienda que pasaba del particular al emperador", de modo que "la naturaleza del vínculo de los colonos privados, hasta ahora anclado a sus obligaciones fiscales, parece sufrir importantes modificaciones a partir de esta época" ${ }^{\prime 4}$.

44 Saumagne, "Du role...", cit., 516-517; De Martino, "Il colonato...", cit., 814 y 817 ; Rosafio, Studi..., cit., 191-192.

45 C. Theod. 9.42.7=C.I. 9.49.7. ARnALDO MARCONE, "Tra schiavitù e colonato. L'agricoltura romana in età imperiale", en Storia dell'agricoltura romana, Roma, 1997, 172. Sobre esta constitución, SAUMAGNe, "Du role...", cit., 559 ss.; JONES, "El colonato romano", cit., 319, n. 23 y GiliberTi, Servi..., cit., 94, la datan en el 369, P. Rosafio, Studi..., cit., 192 ss., la data en el año 365.

46 SAUMAGNe, "Du role...", cit., 560 ss., para quien los "casarii y coloni eran entre las animae las capita bumana" y señala la similitud con D. 1.15.4 pr., si bien en la forma censualis de Ulpiano la denuncia de los arrendatarios por parte de los propietarios no era obligatoria. Esta similitud también es mencionada por MARCONE, "Tra schiavitù...", cit., 172, que observa en la norma una equiparación entre los colonos y los esclavos: "el fundo es considerado desde un punto de vista productivo con fines impositivos. Es característico que a la mención de esclavos y colonos siga la de los bueyes destinados a las labores agrícolas".

47 P. Rosafio, Studi..., cit., 193-194. 
Esta percepción se hace palpable en el análisis de otra constitución del año 371 , también de marcado carácter regional ${ }^{48}$, en la que los emperadores Valentiniano, Valente y Graciano prohibían a los colonos e inquilinos de Iliria y de las provincias vecinas abandonar el campo en el que residían por razón de su origen y agnación, sujetándoseles a las tierras, no por la atadura de los impuestos (en su cualidad de tributarios), sino bajo el nombre y título de colonos (en su condición de colonos), de suerte que si se marchaban o trasladaban, podían ser reclamados, sometidos a prisión y a penas. Se sancionaba también a los propietarios que acogiesen a colonos desconocidos, obligándoles al pago de una multa, cuya cuantía se dejaba a la libre apreciación del juez, y a indemnizar a los propietarios de las tierras abandonadas por los trabajos no realizados y los perjuicios sufridos. Si el fugitivo era un esclavo, la pena prevista era cuatro veces superior, además del resarcimiento al propietario, y si era un liberto se aplicaba la misma pena prevista para los colonos libres ${ }^{49}$.

Algunos autores han considerado esta ley como el origen del colonato adscrito bajoimperial en la medida en que, en palabras de Goffart, supone un cambio esencial con respecto a la situación del colonato precedente dado que, por primera vez, el colono no es vinculado a su origo sino directamente al campo de su familia, se traslada la responsabilidad fiscal al propietario de las tierras y se sustituye la naturaleza fiscal de las penas contra los encubridores de los fugitivos por sanciones de carácter más laboral y pecuniario que serán fijadas por un juez $z^{50}$.

Este punto de vista es matizado por Bravo, precisando que, si bien esta constitución es el primer documento que contiene los rasgos característicos

48 El carácter regional de la regulación relativa a los colonos ha sido señalado, ente otros, por M. RostovTZEFF, s.v. "Kolonat", en Handwörterbuch der Staatswissenschaft, 1909, 913 ss. Paul Collinet, "Le colonat...", cit., 94 ss.. Jerzy Kolendo, Le colonat..., cit., 74 ss. $;$ GreY, "Contextualizing...", cit., 160 ss.

49 C.I. 11.-52-53.1. P. Rosafio, "Coloni...", cit., 456 n. 50; íd., Studi..., cit., 194 ss., precisa cómo el ligamen administrativo de los colonos venía determinado por el origen y el de los inquilinos por la agnatio. Sobre esta constitución, Fustel De COULANGE, Le colonat..., cit., 7 n. 1, señala cómo la ley distingue entre colonos, libertos y esclavos ${ }_{i} \mathrm{CH}$. SAUMAGNE, "Du role...", cit., 511 ss.; DE DOMINICIS, "I coloni...", cit., 88, JONES, "El colonato romano", cit., 320, DE MARTINO, "Il colonato...", cit., 791, BRAVO, El colonato ..., cit., 43, Marcone, "Tra schiavitù...", cit., 171; GiliberTI, Servi..., cit., 104-105; FuenTeSECA, "El colonus...", cit., 83 ss.

50 GOFFART, Caput..., cit., 81 ss., para quien, si bien la ley del año 332 ligaba a los colonos a su origo y no necesarimente a la tierra, esta constitución de 371 les obliga a permanecer en la tierra en lugar de estar obligados al pago de las tasas; ANTONIO GONZÁLEZ BLANCO, "La condición de los colonos en la trama de la sociedad bajoimperial según S. Juan Crisóstomo y la Historia Augusta", Memorias de Historia Antigua, n. ${ }^{\circ}$ 2, 1978, 82, quien comparte la teoría de Goffart, FATÁS-MARCO, "Consideraciones...", cit., 185, que considera que la vinculación del colono al fundo tiende a "afianzarse camino de la adscripción pero a un ritmo difícilmente evaluable aún durante el siglo III y buena parte del IV". 
del colonato, el cambio esencial no radicaba en la instauración de la adscripción legal de los colonos a las tierras que trabajaban, sino "en la pérdida de su carácter contributivo a favor de su vinculación al suelo", lo que permitía al Estado trasladar "las deudas no recaudables de las personas (capitatio) a la productividad de los campos trabajados por ellas haciendo responsables fiscales a sus propietarios (iugatio)". No obstante, precisa el autor, aunque el propietario era el único responsable fiscal ante el Estado de la capitatio debida por su colonos, estos no perdían de facto su capacidad tributaria porque las rentas estipuladas "eran auténticos tributa o fuctiones que el dominus detraía de la economía del colono recurriendo a los procedimientos legalmente establecidos para exigir el pago de las deudas contraídas por los tenentes"

En todo caso, parece claro que esta constitución refuerza aún más el ligamen del colono con el fundo que trabaja revelándose, con carácter general, como determinante del origo en sustitución del poblado o de la aldea, no sólo para los colonos no poseedores sino también para los inquilinos, siendo incluso considerados ambos tipos sirvientes del mismo ${ }^{52}$.

Por otro lado, si hasta el momento esa vinculación se había efectuado en virtud de la capitatio, ahora se justifica por razones administrativas probablemente, como indica JONES, porque dicho impuesto había sido abolido en Iliria, de manera que los colonos, sujetos hasta entonces en virtud de este impuesto general, hubieran recuperado su libertad de movimientos en caso de no llegar a promulgarse esta disposición ${ }^{53}$. Este cambio en el sistema impositivo incrementó, a juicio del autor, la necesidad de mantener a los colonos en las parcelas, dada la escasez de mano de obra agrícola, por lo que el gobierno imperial extendió su vinculación a las fincas, impidiendo su movilidad, incluso en provincias donde antes no había existido, mediante una política legislativa que sigue presentando un marcado carácter regional ${ }^{54}$.

51 C.I. 11.50.2. BRAVO, El colonato..., cit., 34 y 43, precisa que, aunque el propietario era el único responsable fiscal ante el Estado de la capitatio debida por su colonos, estos no perdían de facto su capacidad tributaria porque las rentas estipuladas "eran auténticos tributa o fuctiones que el dominus detraía de la economía del colono recurriendo a los procedimientos legalmente establecidos para exigir el pago de las deudas contraídas por los tenentes". Al respecto, HumberT, s.v. "colonus", cit., 1324; GILIBERTI, Servi..., cit., 94 y 102 ss., para quien el vínculo a la tierra permanece inmutable, cambiando sólo su justificación.

52 GiliberTI, Servi..., cit., 99 ss., entiende que para estos nuevos colonos la residencia fiscal obligatoria era el fundo del locator.

53 JONES, "El colonato romano", cit., 320, quien intuye que ya en el año 371, al igual que ocurrirá en 396 en la Tracia (C.I. 11.51-52-1), la capitatio habría sido abolida en Iliria de manera que los colonos, adscritos hasta entonces en virtud de este impuesto general, hubieran recuperado su libertad de movimientos de no llegar a promulgarse estas disposiciones especiales. En el mismo sentido, GILIBERTI, Servi..., cit., 94 y 102 ss., para quien el vínculo a la tierra permanece inmutable, cambiando sólo su justificación.

54 JONES, "El colonato romano", cit., 323 ss. En el mismo sentido, DE MARTINO, "Il colonato...", cit., 798 y 821. Por su parte, Jean-Michel CarRiÉ, "Le colonat...", cit., 101 ss., considera que cada vez más la base imponible de la capitación se establece en proporción 
La dificultad para encontrar mano de obra pudo inspirar la disposición adoptada en el año 383 por los emperadores Graciano, Valentiniano y Teodosio de inspeccionar las aptitudes físicas y la edad de los mendigos que pedían en público, de forma que los hábiles para el trabajo, si eran esclavos, se adjudicaban en propiedad a los mismos delatores, mientras que si eran libres por nacimiento, eran atribuidos a sus delatores bajo la condición de colonato perpetuo, quedando a salvo la acción de los propietarios frente a los que escondieran a los fugitivos o los empujaran a devenir mendigos ${ }^{55}$.

Idénticas razones tal vez condujeron en el año 400 al emperador Teodosio a ofrecer a los propietarios la posibilidad de poblar sus campos con los sometidos pueblos bárbaros de los Esciros y sus aliados, en régimen de colonato, prohibiendo poseer a los que ya hubieran sido asignados a otros propietarios y recordando las penas para los que acogiesen a los fugitivos ${ }^{56}$.

Y las mismas circunstancias, en un importante contexto de crisis económica y gravosas cargas impositivas, permiten explicar por qué Teodosio en el año 386, en una constitución dirigida al prefecto del pretorio de Oriente, insistía en la prohibición de que los hijos y nietos de los municipales y de los coloni patrimoniales et saltuerenses prestasen el servicio militar o desarrollasen otras funciones, siendo los primeros vinculados a los munera municipalia y los segundos al cultivo de los campos ${ }^{57}$.

Por ello, no es de extrañar que Teodosio procediera en ese mismo año a endurecer las penas contra los que acogieran o escondieran a colonos fugitivos, multándolos con seis onzas de oro si los colonos eran privados, y con el doble (una libra de oro) si eran colonos imperiales ${ }^{58}$.

Y dado que la sujeción de los colonos a las fincas, impidiendo su movilidad, era la principal garantía con la que contaban los terratenientes, como indica Jones, estos utilizaron su posición predominante en los círculos gubernativos para conseguir que el gobierno imperial la impusiera, incluso en provincias donde antes no había existido, por medio de una política legislativa que sigue presentando un marcado carácter regional ${ }^{59}$. No en vano, afirma el autor,

a las unidades de tierra, hasta el punto de que en algunas provincias como la Tracia será abolida en el año 393 y en la Galia ya no se entenderá el sentido de la capitatio en el último año del siglo IV. C. Theod. 11.1.26.

55 C. Theod. 14.18.1=C.I. 11.26.1. JONES, "El colonato romano", cit., 328.

56 C. Theod. 5.6.3. DE MARTINO, "Il colonato...", cit., 796, para quien constituyen una prueba de la distinta condición de los colonos y de los esclavos; ROSAFIO, Studi..., cit., 196-197 y 205-206; GREY, "Contextualizing...", cit., 162 ss.

57 C.I. 11.64.1. HumberT, s.v. "colonus", cit., 1325; De Dominicis, "I coloni...", cit., 96 n. 34, Rosafio, Studi..., cit., 197 n. 34.

58 C. Theod. 5.17.2=C.I. 11.64.2. HumBerT, s.v. "colonus", cit., 1325; PASQuale Rosafio, Studi..., cit., 197-198.

59 JONES, "El colonato romano", cit., 323 ss. En el mismo sentido, DE MARTINO, "Il colonato...", cit., 798 y 821 . 
cuando en el año 393 se introduce el colonato perpetuo en Palestina, Teodosio deja muy claro a favor de quién se dicta la ley, al afirmar que se concede a los terratenientes de esta provincia la misma ventaja de la que disfrutaban en otras mediante la prescripción del carácter perpetuo de todos los colonos y su sujeción al dueño de los fundos, que tenía plena autoridad para reclamarlos, de manera que ninguno pudiera alegar su condición de libre o vagabundo para marcharse, ni ser acogido sin sanción ${ }^{60}$.

A su vez, sólo tres años después, se extiende a la Tracia este ius colonatus perpetuo, identificado con el ius originarium, para evitar las consecuencias negativas que la eliminación de la capitatio pueda provocar en la organización productiva de los campos. De ahí que se advierta que no se concede a los colonos exentos libertad para desplazarse puesto que están sujetos a su origo $\mathrm{y}$, aunque sean ingenuos, se les considera esclavos de la misma tierra para la que nacieron, sin que puedan retirarse a voluntad ni permutar los lugares, permitiendo al propietario que ejerza derecho sobre ellos el cuidado de patrono y la potestad de señor. Se establece además la pena de dos libras de oro contra el que acogiera o retuviera a un colono ajeno, en concepto de indemnización al propietario, y la obligación de restituírselo, junto con su peculio y sus agnados, incrementándose las penas impuestas en el año 386 consistentes en media libra de oro si se trataba de un colono perteneciente a un dominio privado, y de una libra de oro si era un tenente de los dominios imperiales ${ }^{61}$.

60 C.I. 11.50-51-.1. JONES, "El colonato romano", cit., 323 ss. En el mismo sentido, GILIBERTI, Servi..., cit., 100 ss., afirma que en la segunda mitad del siglo IV el colonato entendido como la adscripción a un específico fundo con fines fiscales aún no tenía alcance general. En Egipto el colonato se había difundido poco a causa del tradicional régimen de los publici vici, responsables colectivamente de los impuestos. Sólo a comienzos del siglo V parecen coexistir dos especies de colonos: los ligados al pueblo de origen con ocasión del impuesto fundiario, y los de nuevo tipo para los cuales la residencia fiscal obligatoria era representada por el fundo del locutor. Con esta constitución, de entre el año $380 \mathrm{y} \mathrm{el}$ 390, el régimen del colonato se extiende a Palestina, uniformándola a otras provincias, vinculando a los colonos eternamente al fundo por dos motivos: porque son campensinos y deben permanercer siempre tales, y porque se quiere evitar que el fundo del patrono sea abandonado. Vid., igualmente, SAUMAGNE, "Du role...", cit., 517 y 536, quien la data en el año 386; Bravo, "La condición...", cit., 82; De DominiCis, "I coloni...", cit., 88, considera que la ley anterior sería la constitución de Constantino del 332; DE MARTINO, "Il colonato...", cit., 791 y 820; MARCONE, "Tra schiavitù...", cit., 172; ROSAFIO, "Coloni...", cit., 459; idem, Studi..., cit., 198-199, quien duda si la norma precedente es C.I. 11.52-53-.1 o C.I. 11.47-48-.6; GREY, "Contextualizing...", cit. 165 ss.; FuenTESECA, "El colonus...", cit., 82 ss.

61 C.I. 11.51-52-.1. Vid. C. Theod. 5.17.2=C.I. 11.64.2. SAUMAGNE, "Du role...", cit., 511 ss y 535; A. González Bravo, "La condición...", cit., 82; JONES, "El colonato romano", cit., 320, la data entre el 393 y el 395; DE MARTINO, "Il colonato...", cit., 791; BrAVO, El colonato..., cit., 43, RoSAFIO, Studi..., cit., 199 ss., que data la medida en el año 393, fecha apuntada también por GREY, "Contextualizing...", cit., 167 n. 57; GILIBERTI, Servi..., cit., 104-105. 
Más aún, en ese mismo año 396 d.C., según recoge Humbert, el emperador Arcadio impide a estos coloni censibus adscripti disponer libremente de su patrimonio e interponer acciones civiles contra los propietarios, exceptuando los casos de exacciones indebidas ya previstas por Constantino ${ }^{62}$, restringiendo la actuación por vía criminal sólo al supuesto de injurias sufridas personalmente o por sus familiares vinculándolos por deuda de su condición a quienes deben las contribuciones anuales ${ }^{63}$.

Y otras leyes posteriores les prohibieron unirse al ejército o desempeñar cargos públicos o entrar en el sacerdocio sin el consentimiento de su patrón, reduciéndolos casi a una condición servil ${ }^{64}$.

Sin embargo, pese a las importantes restricciones a su libertad, compartimos la opinión de ROSAFIO sobre la distinta condición jurídica de los colonos, esclavos y libertos. Ahora bien, como reconoce el autor, venido a menos el nexo que vinculaba a los colonos como contribuyentes, su libertad de movimientos es limitada mediante el ius originarium, de manera que "no es ya el vínculo fiscal el que lo liga al origo, sino el origo mismo el que determina el vínculo",

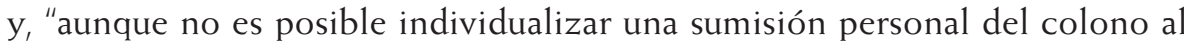
propietario, la relación que se establece entre ellos no es ya la propia de un contrato de locatio-conductio" 65 .

En realidad, como precisa Bravo, sólo aquellos coloni censibus adscripti que evolucionen hacia formas de dependencia personal vinculadas a la condición adscripticia se encontrarán en un situación más precaria próxima a la esclavitud, sin que sea del todo correcto establecer la equiparación semántica entre originales u originarii occidentales y adscripticii orientales ${ }^{66}$, debiendo tenerse en cuenta que el término originarii desaparece de los textos jurídicos a mediados del siglo $\mathrm{V}$, mientras que el de adscripticii, salvo interpolación posterior, no es utilizado para indicar una concreta situación de colonato en la parte oriental hasta la segunda mitad de siglo. Además, aunque en algunas fuentes se haga referencia a los campesinos adscripti in censibus, la condicio adscripticia no será propiamente regulada hasta Justiniano ${ }^{67}$.

62 Vid. C.I. 11.50.1. HumberT, s.v. "colonus", cit., 1322 ss.

63 C.I. 11.50.2. HumberT, s.v. "colonus", cit., 1322 ss.; SAUMAGNE, "Du role...", cit., 543 ss.; GANSHOF, "Le statut...", cit., 274 ss.; JONES, "El colonato romano", cit., 323 ss.; DE MARTINO, "Il colonato...", cit., 794, GILIBERTI, Servi..., cit., 108 ss.; Rosafio, "Coloni...", cit., 454 n. 38; idem, Studi..., cit., 202 ss., para quien el término peculium fue introducido en la interpretatio; GREY, "Contextualizing...", cit., 167 y 172, para quien el término peculio es usado metafóricamente y los límites a su disposición son una garantía pública para procurar que los colonos puedan pagar los impuestos.

64 C.I. 11.47-48-.18; C.I. 12.34-33-.3; C.I. 1.12.6 § 5. HuMBERT, s.v. "colonus", cit., 1325 JONES, "El colonato romano", cit., 323 ss.; GILIBERTI, Servi..., cit., 113 ss.

65 Rosafio, Studi..., cit., 200 ss.

66 Esta equiparación es realizada, entre otros, por JONES, "El colonato romano", cit., 326 ss.; GiliberTi, Servi..., cit., 100, GreY, "Contextualizing...", cit., 173. 


\section{II.1. LOS ORIGINARII DE LA PARTE OCCIDENTAL DEL IMPERIO EN EL SIGLO V}

La mejor situación de los colonos originarios occidentales frente a los adscripticios orientales se observa en algunas constituciones de comienzos del siglo $\mathrm{V}$ en las que se establece que los primeros podrían liberarse de su obligación perpetua y hereditaria de cultivar la tierra por aplicación de las reglas de la prescripción. Ya en el año 400, Honorio estableció en una constitución dirigida a Vicentio, prefecto del pretorio de las Galias, que se podía salir de la condición de colonato o inquilinato como consecuencia de la praescriptio longi temporis, después de treinta años si el colono permanecía en la misma provincia, o de cuarenta si se encontraba en otra provincia. Más allá de estos plazos el emperador advertía que a nadie le era lícito, ya se tratase de la res domenica o de un privado, reclamar a un colono o inquilino ${ }^{68}$.

A partir del año 419 se sancionó con carácter general la aplicación de la prescripción a los colonos originales u originarios y a los inquilinos, de manera que si el propietario dejaba transcurrir sin reclamarlos el plazo de treinta años si se trataba de hombres, o de veinte años en el caso de las mujeres, perdía los derechos sobre ellos ${ }^{69}$.

Pero el abuso de esta posibilidad por parte de los originales que, como describe De Dominicis, huían de su condición para convertirse en campesinos libres en las tierras de otro propietario, condujo a Valentiniano III a establecer que aquellos que se liberaban de su propietario por ausencia de treinta años pasarían a ser originales de su nuevo propietario o de aquel a quien hubieran servido por más tiempo o en los últimos años de los mencionados treinta, si se habían ido trasladando de una tierra a otra ${ }^{70}$.

C. Theod. 12.19.2=C.I. 11.66.6. HumberT, s.v. "colonus", cit., 1324-1325; SAUMAGNE, "Du role...", cit., 502, 507, 518 ss.; JONES, "El colonato romano", cit., 327 n. 57; DE MARTINO, "Il colonato...", cit., 792 n. 15; GiliberTI, Servi..., cit., 113, ROSAFIO, Studi..., cit., 205. Un estudio profundo de esta constitución lo realiza CUENA BOY, "'Causa originis"...", cit., 85-86. En su opinión, las causa originis et proprietas (C. Theod. 4.23.1) y quaestio colonatus aut inquilinatus (C. Theod. 12.19.2-3) "no son significativas de ninguna diferencia reseñable en lo que atañe al procedimiento. No obstante, como mera conjetura cabría sugerir que la primera se correspondía con aquellos pleitos en los que no se discutía la condicio colonaria del fugado, sino sólo su origo en esta o en aquella finca. En cambio, la segunda podría ser más apropiada para aquellos otros casos en los que se debatía el propio estatus de colono".

69 C. Theod. 5.18.1=C.I. 11.47-48-.1. HuMBERT, s.v. "colonus", cit., 1324-1325; DE DOMINICIS, "I coloni...", cit..., 90 ss.; De MARTINO, "Il colonato...", cit., 792 n. 15; GILIBERTI, Servi..., cit., 113 n. 25; GREY, "Contextualizing...", cit., 163 ss., señala cómo en la Novela 27 de Valentiniano III el colonato es considerado un privilegio. Para FranCisCo CuENA Boy, "'Causa originis"...", cit., 86, a diferencia de en la anterior, en esta "la causa originis se desarrolla entre particulares, sin implicación por tanto de interés público alguno". La ley aporta algunos cambios: el plazo de prescripción, la posibilidad de demandar directamente al presunto colono, así como de ordenar su restitución sin dictar sentencia ni permitirle defensa cuando existiera certeza absoluta sobre su condicio.

70 Novellae Valentiniani III, 31; Novellae Maioriani, 7; Novellae Severiani, 2. De DomINICIS, "I colo- 
Toda esta amplia legislación prueba, según Bravo, la incapacidad de los emperadores occidentales para corregir las situaciones ilegales de evasión fiscal o que hacían difícil la recaudación de los impuestos por los funcionarios imperiales, por lo que se vieron obligados a encomendar dicha recaudación a los propios terratenientes, favoreciendo "el desarrollo del colonato y el afianzamiento de las relaciones de patrocinio", mediante las cuales los colonos trataban de liberarse de las cargas impositivas o de las presiones de los acreedores privados ${ }^{71}$.

Este sometimiento condujo a Salviano ${ }^{72}$ a afirmar su conversión en esclavos, opinión que no es compartida por San Agustín, que opone la ingenuitas de los colonos a la servitus de los esclavos y los define como "cultores que trabajan la tierra de otro y que deben su condición al suelo en el que nacieron"73.

Ahora bien, como afirma Rosafio, si en una carta dirigida a Eustaquio, con motivo de la venta de los hijos de colonos, se pregunta si el adquirente tiene un mayor derecho que el que tenía el propietario del fundo y si el poseedor del fundo puede reducir a la esclavitud a los colonos o a sus hijos, aunque está claro que la primera pregunta es un argumento a favor de la libertad del hijo vendido, la segunda prueba que en la práctica existía la tendencia de transformar a los colonos en esclavos y tratarlos como tales, aproximación que también se desprende de las fuentes jurídicas que no llegan, sin embargo, a equipararlos ${ }^{74}$.

En cualquier modo, como anticipábamos supra, las referencias a estos originarii occidentales desparecen a mediados del siglo $\mathrm{V}$ mientras que en la parte oriental comienza a configurarse la condición adscripticia cuya regulación ultima Justiniano.

ni...", cit., 91; SAUMAGNE, "Du role...", cit., 522, JONES, "El colonato romano", cit., 327, GiliberTi, Servi..., cit., 113.

71 Bravo, El colonato..., cit., 44 ss. Sobre las relaciones de patrocinio, HumberT, s.v. "colonus", cit., 1325; ANGelo Segré, "The Byzantine Colonate", Traditio, n. ${ }^{\circ}$ 5, 1947, 118 ss. afirma que mientras en Oriente se encontraban colonos vinculados a la tierra, colonos libres, colonos sub patrocinio y colonos adscritos, en Occidente todos los colonos eran sub patrocinio; GILIBERTI, Servi..., cit., 123 ss., afirma que el patrocinio, poniendo en crisis el control del territorio por parte de la autoridad imperial, terminará por socavar el sistema del colonato y prefigura la servidumbre medieval, ROSAFIO, Studi..., cit., 206 ss., analiza la distinta situación de los conductores y la de los colonos en el siglo $\mathrm{V}$.

72 Salviano, De Gubernatione Dei, V. 26, 38-39 y 45. MARCONE, "Tra schiavitù...", cit., 172; Blázquez, J.M.-Blanco Frejeiro, A., La sociedad del Bajo Imperio en la obra de Salviano de Marsella, Madrid, 1990, 47 ss.; GILIBERTI, Servi..., cit., 133.

73 San Agustín, De Civitate Dei, X. 1, 2, 7. Bravo, El colonato..., cit., 15-18 y 44; GiliberTI, Servi..., cit., 80.

74 San Agustín, Epistolae. A juicio de Pasquale Rosafio, Studi..., cit., 213-214, la duda no es debida a su falta de conocimiento jurídico, sino al hecho de que el legislador había desvalorizado tanto el estatuto personal de colono que era cuestionable si el mismo podía seguir siendo considerado un hombre libre. En el mismo sentido, DE MARTINO, "Il colonato...", cit., 77 n. 49, indica cómo en C. Theod. 9.21.4 y C. Theod. 2.31.1 se observa que el colono está un poco más arriba que el esclavo. Vid. GILIBERTI, Servi..., cit., 11 ss. 


\section{II.2. LOS ADSCRIPTICII DE LA PARTE ORIENTAL DEL IMPERIO}

Según De Martino, el término adscripticius se registra por primera vez en una ley del año $466^{[75]} \mathrm{y}$, aunque su equivalente griego "enagraphos" había sido utilizado por Marciano al dirigirse al Concilio de Calcedonia en el año 451, el mismo no se identifica todavía con adscripticius sino con originarius, reputándose interpolado el término en las constituciones anteriores a esta fecha ${ }^{76}$.

Las primeras menciones no se refieren específicamente al colonato sino a la prohibición de que a los colonos se les dé asilo eclesiástico, al igual que a los esclavos o libertos, dada su condición común de personae domesticae ${ }^{77}$ o su imposibilidad de acceder a cargos o funciones eclesiásticas sin el consentimiento del dueño del fundo ${ }^{78}$, no existiendo ninguna ley del siglo $\mathrm{V}$ que permita comprender en qué se diferencian los colonos adscripticii de otras clases de colonos $^{79}$.

Sólo en una constitución del emperador Anastasio del año 500 hay una clara distinción entre las categorías de colonos, pero esta ley sintetiza un pasaje de las Basílicas ${ }^{80}$, por lo que se puede dudar de su autenticidad; aunque no de su existencia, ya que la misma es citada y confirmada por Justiniano en la parte que concierne al estado de los hijos de los $\operatorname{colonos}^{81}$.

En esta ley se diferencia entre los "georgoi" o campesinos plenamente libres; los "misthotoi" o arrendatarios libres, que conservan su capacidad para poseer inmuebles y que eran transformados en colonos al término de la praescriptio de treinta años, estando sujetos a satisfacer el tributum; y los "enagraphoi" o adscripticii, que no tienen capacidad para poseer bienes inmuebles, cuya pertenencia y no simple disponibilidad es del propietario ${ }^{82}$.

Justiniano, como señala De Dominicis, retoma esta ley y la aplica también a los hijos de los colonos aunque no hubieran permanecido treinta años (o cuarenta, según el caso) en el fundo, añadiendo que ellos no debían ser gra-

75 C.I. 1.12 .6$.

76 Se considera interpolado el término en C.I. 8.51.1; C. Theod. 2.25.1; C.I. 11.47-48-.6. DE MARTINO, "Il colonato...", cit., 797-798. Al respecto, DE DOMINICIS, "I coloni...", cit., 87 ns. 3-4; JONES, "El colonato romano", cit., 326; BRAVO, El colonato..., cit., 15 ss.

77 C.I. 1.12 .6 .

78 C.I. 1.4 .36 .

79 C.I. 1.3.36; C.I. 11.69.1; C.I. 2.4.43; C.I. 12.19.12; y C.I. 11.48.19. De MarTinO, "Il colonato...", cit., 798.

80 C.I. 11.47-48-.19=Basilici, 5.55.18.

81 C.I. $11.47-48-.23 \S 1-2$.

82 SaUmagne, "Du role...", cit., 497, 519 y 542, DE DOMINICIS, "I coloni...", cit., 88; JONES, "El colonato romano", cit., 329; DE MARTINO, "Il colonato...", cit., 799, GiLiberTi, Servi..., cit., 100 y 107 ss.,). VID. GREY, "Contextualizing...", cit., 173, con dudas sobre su autenticidad. 
vados por una peor condición y, por consiguiente, prohíbe a los propietarios imponerles innovaciones o el ejercicio de la violencia ${ }^{83}$.

Y si las innovaciones o la violencia eran probadas ante el juez, el gobernador de la provincia debía velar por el resarcimiento del daño y la observancia de la costumbre antigua en la prestación del rédito, sin que en ningún caso el colono tuviera la facultad de abandonar el fundo, ni tampoco sus descendientes que, con independencia de su sexo o edad, debían permanecer en el fundo en el mismo modo y condiciones que sus padres ${ }^{84}$.

Por tanto, como constata Bravo, aunque en época de Anastasio la prescripción de treinta años todavía tenía carácter liberatorio, como lo prueban algunas constituciones relativas a la denominada lex Anastasiana, algunos años después Justiniano cambió su sentido, sancionando que el ocupante libre que permaneciera en la tierra por más de treinta años pasaba a quedar vinculado a la misma en las condiciones preexistentes, incluso en relación con las prestaciones de la renta ${ }^{85}$

Estos colonos, como indica Jones, podían disponer libremente de su propio patrimonio, actuar procesalmente contra los propietarios $\mathrm{y}$, en general, estaban libres de todas las trabas de la condición adscripticia, excepto de la prohibición de irse, que Justiniano sólo autorizó si conseguían en propiedad una granja que requiriera su dedicación en exclusiva y que fuera suficiente para mantenerlos ${ }^{86}$.

Pero a diferencia de estos colonos que tenían la posibilidad de prescribir el vínculo, Justiniano sancionó la incapacidad patrimonial de los adscripticii más allá de la tenencia de un peculium cuya disposición requería el consentimiento del propietario, así como su carácter hereditario e imprescriptible, situación de la que sólo se podía salir legalmente haciéndose obispo ${ }^{87}$.

83 C.I. 11.47-48-.23§1. De Dominicis, "I coloni...", cit., 90 ss.; HumberT, s.v. "colonus", cit., 1324-1325; SAUMAGne, "Du role...", cit., 498, 524 ss. y 568 ss.; JONES, "El colonato romano", cit., 329; DE MARTINO, "Il colonato...", cit., 799; BRAVO, El colonato..., cit., 18 y 44.; GiliberTI, Servi..., cit., 113 ss.; FuenteSeCA, "El colonus...", cit., 80 ss.

84 C.I. 11.47-48-.23§1, in finem y $\$ 2$, sobre las penas contra los que acojan a fugitivos, HuMBERT, s.v. "colonus", cit., 1324-1325; SAUMAGNE, "Du role...", cit., 498, 524 ss. y 568 ss.; JONES, "El colonato romano", cit., 329; DE MARTINO, "Il colonato...", cit., 799; BRAVO, El colonato..., cit., 18 y 44; FUENTESECA, "El colonus...", cit., 80.

85 C.I. 11.47-48-.23 pr. Bravo, El colonato..., cit., 44. En este sentido, De Dominicis, "I coloni...", cit., 90. Vid. JONES, "El colonato romano", cit., 328-329; GILIBERTI, Servi..., cit., 113, para quienes ya con Anastasio la prescripción tenía efecto adquisitivo de la condición de colono.

86 Novellae Iustiniani, 162.2. JONES, "El colonato romano", cit., 329, HUMBERT, s.v. "colonus", cit., 1324-1325; De Dominicis, "I coloni...", cit., 95-96; GILIBERTI, Servi..., cit., 114.

87 Novellae Iustiniani 123.4. HuMBERT, s.v. "colonus", cit., 1324-1325; GANSHOF, "Le statut...", cit., 274 ss.; DE DOMINICIS, "I coloni...", cit., 97; JONES, "El colonato romano", cit., 328 , Giliberti, Servi..., cit., 110 y 114 n. 31 GiliberTi, Servi..., cit.., 114 n. 31; Francisco CuEna BoY, "Yanaconazgo...", cit., 8 n. 66; Vid. Novellae Iustiniani 127; y Novellae Iustiniani 
Por ello, como entiende De Dominicis, dado que el contrato en virtud del cual una persona libre se vinculaba a otra como adscripticius suponía una "deterior fortuna" respecto a un libre, se dictaron rigurosas normas para decretar su validez, indicando que no bastaba la conductio o un documento escrito cualquiera, sino que tales actos debía ser confirmados por una inscripción en el censo o por otros medios legales de prueba ${ }^{88}$

Sólo tras la confessio o, más propiamente, la depositio de un acto unilateral en virtud del cual un colono se dirigía a las autoridades públicas renunciando a las ventajas de la ingenuitas, entraba espontáneamente en la clase de los adscripticios y contraía la doble obligación para sí y sus descendientes de cultivar un fundo y de residir en é ${ }^{89}$.

En efecto, el carácter imprescriptible del vínculo afectaba también al hijo del adscripticius que no se liberaba de su condición aunque hubiera estado ausente del fundo y de las tareas agrícolas durante treinta o, en su caso, cuarenta años, permitiéndolo el propietario porque se le daba cumplimiento por su padre, sino que subsistía su derecho a reclamarlo cuando el padre muriera o no valiese para el trabajo ya que, según rezaba la constitución, mientras los ascendientes, descendientes o cognados residieran en el fundo, se entendía que aquel también residió allipo.

La diferencia entre ambas categorías de colonos se observa también en una amplia legislación regulativa de los matrimonios entre adscripticii y libres y la condición de los hijos nacidos en su seno ${ }^{91}$, en la que se confronta la

22.17; SAumagne, "Du role...", cit., 540 ss.; De Martino, "Il colonato..."., cit., 800; GreY, "Contextualizing...", cit., 173, quienes, pese a las restricciones, les reconocen un cierto poder de disposición.

88 C.I. 11.47-48-.22. De DOMINICIS, "I coloni...", cit., 89. Al respecto, HumberT, s.v. "colonus", cit., 1324, señala la exigencia de una declaración formal apud acta; SAUMAGNE, "Du role...", cit., 504, 512 ss. y 568 ss.; JONES, "El colonato romano", cit., 328 ss.; De MARTINO, "Il colonato...", cit., 799, exigía el depósito del documento escrito en un archivo público y su confirmación mediante inscripción registral, y GILIBERTI, Servi..., cit., 112, entienden que la condición adscripticia debía ser demostrada mediante documentos, no bastando ni el contrato de arrendamiento ni la declaración unilateral del colono reconociéndose adscripticio: "el procedimiento más correcto era realizar una declaración de arrendamiento (scriptura) y sucesivamente una confessio formal o el depósito del documento".

89 De Dominicis, "I coloni...", cit., 89. En el mismo sentido, SAUmaGne, "Du role...", cit., 514 .

90 C.I. 11.47-48-.22§1. De Dominicis, "I coloni...", cit., 91-92; SAUMAGne, "Du role...", cit., 522 ss.; DE MARTINO, "Il colonato...", cit., 799. Vid. JONES, "El colonato romano", cit., 328 , que parece relacionar esta constitución con los colonos vinculados por el transcurso de la prescripción.

91 C.I. 11.47-48-.21; C.I. 11.47-48-.24; C.I. 7.24.1; Novellae Iustiniani 22.7, 54 pr.-1, 156, 157 y 162; Novellae Iustini II, 6; Novellae Tiberi II, 13. 
condición de los adscripticios con la de los esclavos, más que para equiparlos, como postula GANSHOF ${ }^{92}$, para diferenciarlos, como sostiene De Martino ${ }^{93}$.

Conforme a esta regulación, siguiendo la síntesis efectuada por De Dominicis, al igual que los nacidos de personas adscripticias y personas esclavas seguían la condición de la madre ${ }^{94}$, también los nacidos en el seno de un matrimonio entre personas libres y adscripticias eran libres si la madre era libre, y eran adscripticios si la madre era adscripticia ${ }^{95}$.

Sin embargo, el creciente número de matrimonios mixtos, de los cuales nacían descendientes libres - con la consiguiente disminución de los adscripticios-, condujo a Justiniano a prohibirlos, permitiendo al propietario que, bien él mismo directamente o bien por conducto del gobernador de la provincia, efectuase la separación de la mujer culpable que recibía una moderada corrección, no obstante, presionado por varias prefecturas, agravó poco

92 GANSHOF, "Le statut...", cit., 274 ss., observa en esta legislación la aproximación de todos los colonos a la esclavitud. Así parece entenderlo también JONES, "El colonato romano", cit., 329, si bien en relación sólo con los adscripticios ${ }_{i}$ PÉREZ SÁNCHEZ, D., "Legislación y dependencia en la España visigoda", AA.VV., Romanización y Reconquista en la Península Ibérica: nuevas perspectivas, Salamanca, 1998, 228-230, habla de una progresiva nivelación, GILIBERTI, Servi..., cit., 107 ss., para quien la única diferencia entre los esclavos y los adscripticios es que el patrón puede liberar a los primeros sin atribuirles ningún peculio, mientras que para conceder la plena libertad a los adscripticios les tienes que dejar una propiedad de tierra suficiente que permita su pleno empleo.

93 De Martino, "Il colonato...", cit., 791, 800 y 802. Por su parte, SAUmaGne, "Du role...", cit., 499 ss., 530-533 y 547 ss., establece una jerarquía de estados personales: colonos, adscripticios y esclavos, reconociendo en esta escala la aproximación a la esclavitud de los adscripticios; Jean-Michel CarRIÉ, "Le riforme...", cit., 310, y Rosafio, "Coloni...", cit., 453, hablan de estatuto intermedio entre los libres y los esclavos; DE DOMINICIS, "I coloni...", cit., 97 ss., afirma que Justiniano mostró humanidad y preocupación hacia todos los colonos; EIBACH, Untersuchungen..., cit., 30-32 y 114-131, postula que el colono bajoimperial seguía siendo fundamentalmente un arrendatario a quien se reconoce cierta independencia, sin que haya pruebas de su progresiva servidumbre, y que en la época justinianea el término colono no aludía a una clase concreta sino a la población campesina en general, MARCONE, "Tra schiavitù...", cit., 172 ss., señala la condición particularmente baja de los adscripticios orientales, CUENA BOY, "Yanaconazgo...", cit., 9, reconoce que la condición adscripticia se parece cada vez más a la servil, sin llegar a identificarse ; GREY, "Contextualizing...", cit., 155 ss., afirma que el registro de los agricultores no supuso un status personal ni el mismo es resultado de su degradación formal a una posición de esclavitud o cuasi esclavitud.

94 C.I. 11.47-48-.21. De Dominicis, "I coloni...", cit., 94 ss.; SAUmagne, "Du role...", cit., 499 ss. y 530 ss.

95 C.I. 11.47-48-.24. De DOMINICIS, "I coloni...", cit., 94 ss, HuMBERT, s.v. "colonus", cit., 1323-1325; SAUMAGNE, "Du role...", cit., 499 ss. y 530 ss.; GANSHOF, "Le statut...", cit., 274 ss.; JONES, "El colonato romano", cit., 329; DE MARTINO, "Il colonato...", cit., 791, 800 y 802, CUENA BOY, "Yanaconazgo...", cit., 8 n. 70, señalan la facultad del propietario de separar al adscripticio de la mujer libre con la que se ha casado para impedir la disminución paulatina de aquellos; GILIBERTI, Servi..., cit., 114 ss. 
después las sanciones declarando nulos los matrimonios mixtos y, con ellos, las donaciones esponsalicias y las dotes ${ }^{96}$.

Asimismo, en el año 539, ante los intentos de aplicar la disposición de C.I. 11.47-48-.24 a los hijos de los adscripticios nacidos con anterioridad a su promulgación y reclamar su condición de libres, Justiniano tuvo que matizar que la misma no tenía carácter retroactivo, por lo que se aplicaba sólo a los nacidos después de su promulgación ${ }^{97}$.

Y, consciente de que los matrimonios mixtos no sólo tenían lugar, sino que eran, de facto, tolerados, precisó que los hijos de una mujer libre y de un adscripticio, si bien eran ingenui, dada la condición libre de la madre, quedaban obligados a permanecer en la tierra en que nacieron por la condición adscripticia del padre ${ }^{98}$.

La incapacidad patrimonial, el carácter hereditario e imprescriptible del vínculo y la normativa matrimonial expuestos ponen de manifiesto la peor condición de los adscripticii que, como señala De Martino, sólo es explicable en virtud de "una evolución histórica que convirtió realmente en perpetuo el estado del colono, desde el momento en que no se reconocía la posibilidad de modificarlo con la prescripción, necesitándose una voluntaria y solemne decisión del sujeto empujado a asumir para sí y su descendencia la condición permanente de colono de un fundo determinado" ${ }^{\prime \prime 9}$.

Se trataba, en su opinión, de nuevos colonos que, tal vez desde Anastasio, eligieron su estado para asegurarse la certeza de un trabajo estable cuya condición no puede equiparase a la del esclavo ya que se trataba de una institución nueva, a caballo entre la libertad y la esclavitud, que consistía en un vínculo

96 C.I. 7.24.1, Novellae Iustiniani, 22, cap. 17 pr., año 535. DE DominiCIS, "I coloni...", cit., 95; Saumagne, "Du role...", cit., 534, Giliberti, Servi..., cit., 116 ss.

97 Novellae Iustiniani, 54 pr.-1 (a. 537). De DominICIS, "I coloni...", cit., 95. Al respecto, HumBERT, s.v. "colonus", cit., 1323-1325; SAUMAGNE, "Du role...", cit., 534; JONES, "El colonato romano", cit., 329; DE MARTINO, "Il colonato...", cit., 791, 800 y 802; FRANCISCO CuENA Boy, "Yanaconazgo...", cit., 8 n. 70, GiliberTI, Servi..., cit., 116 ss.

98 Novellae Iustiniani, 162. DE DOMINICIS, "I coloni...", cit., 95-98, señala además una última intervención (Novellae Iustiniani, 162. App. I), en el año 400, relativa a Iliria, en la que, a pesar de las sanciones, seguía vigente la constitución C.I. 11.47-48-.24, lo que provocaba el abandono masivo de los hijos nacidos de adscripticios o colonos y mujeres libres ya que eran considerados libres, por lo que aplicó a esta prole la condición del padre. En todo caso, el autor duda sobre la eficacia de las disposiciones puesto que los emperadores posteriores continuaron legislando sobre la materia. En el mismo sentido, JONES, "El colonato romano", cit., 329, señala cómo, a pesar de estas leyes, siguió la inquietud de los terratenienes africanos que, a la muerte de Justiniano, solicitaron a Justino II que las confirmara (Novellae Iustiniani II, 6), repitiendo la petición a su sucesor Tiberio Constantino (Novellae Tiberi II, 13). Al respecto, HUMBERT, s.v. "colonus", cit., 1323-1325; SAUMAGNE, "Du role...", cit., 499 ss. y 530 ss.; JONES, "El colonato romano", cit., 328-331; DE MARTINO, "Il colonato...", cit., 791, 800 y 802, Bravo, El colonato..., cit., 45; GiliberTI, Servi..., cit., 116 ss.

DE MARTINO, "Il colonato...", cit., 800 y 802. 
con la tierra y, en consecuencia, en una forma de sujeción al propietario de la misma, bien diversa de la del esclavo que no puede considerarse, pese a todas las limitaciones, el origen de la gleba medieval ${ }^{100}$.

\section{CONSIDERACIONES FINALES}

En el presente trabajo hemos observado que, si bien la heterogeneidad jurídica existente en el colonato bajoimperial resulta innegable, se puede afirmar que estuvo caracterizado por dos rasgos esenciales: uno de orden fiscal, en cuanto grupo sujeto al impuesto de la tierra que cultivaba, estuviera o no adscrito a ella; y otro de orden social, en cuanto clase de bumilliores que sufrió una progresiva degradación sociopolítica y económica con la consiguiente pérdida de derechos.

El contrato de arrendamiento será sustituido por otros sistemas perpetuos de producción agrícola, transformándose la relación contractual en una relación de dependencia entre el colono y la parcela de tierra que cultiva. Esta transformación vino impulsada por la necesidad de asegurar la explotación de las tierras, impidiendo su abandono, y por la reforma fiscal que extendió a todo el Imperio el tributum capitis y unificó el impuesto territorial y el personal (iugatio-capitatio) remitiendo la responsabilidad fiscal, no a las fortunas personales valoradas en dinero, sino a los principales recursos de cada dominio censado, a sus tierras (iugatio), animales y hombres (capitatio).

Ello supuso que los colonos quedasen sujetos a su lugar de procedencia (origo) en cuanto contribuyentes de la capitatio, así como que se restringiera legalmente su libertad de movimientos para evitar la evasión fiscal, dando lugar a la categoría denominada coloni originarii. A lo largo de la segunda mitad del siglo IV, razones administrativas determinan que estos colonos sean vinculados de manera perpetua y hereditaria, no a su origo en su cualidad de tributarios, sino directamente al suelo cultivado en su condición de colonos, sustituyéndose la naturaleza fiscal de las penas contra los encubridores de los

100 De MARTINO, "Il colonato...", cit., 800 y 802, reconoce que en las fuentes romanas se hablaba de gleba y de esclavitud de la tierra (C.I. 11.47-48-.15, 11.47-48-.3, C. Theod. 11.1.12), antes de que Irnerio acusara el término servus glebae, pero entiende que es arriesgado afirmar que en este colonato se encuentra el origen de la esclavitud de la gleba medieval, una continuidad que parece apuntar HuMBERT, s.v. "colonus", cit., 1325, al afirmar que "los colonos se transformarán en siervos en la época feudal". La opinión de De Martino es seguida por GILIBERTI, Servi..., cit., 14 y 18, para quien es impropio unificar el colonato tardo-antiguo y la servidumbre medieval bajo la etiqueta omnicomprensiva de "servidumbre de la gleba". Al respecto, FinLEY, M., "The Study of the Ancient Economy. Further Thoughts", Opus, 3, 1984, 6, también afirma que el colono, si bien ya no era el agricultor libre, no era todavía el siervo de la gleba feudal. En el mismo sentido, MARCONE, Il colonato..., cit., 123 ss. 
fugitivos por sanciones de carácter laboral y pecuniario. Esta medida favorece un cambio en el sistema impositivo, en virtud del cual la base imponible de la capitación se establece cada vez más en proporción a las unidades de tierra y la responsabilidad fiscal se traslada al propietario de las mismas.

A partir del siglo $\mathrm{V}$, en la parte occidental, el ligamen al suelo de los colonos originarios queda sujeto a las reglas liberatorias de la prescripción, y en la parte oriental comienza a configurarse la condición adscripticia cuya regulación concluye Justiniano. A tal fin establece su carácter hereditario e imprescriptible, su incapacidad patrimonial, una rígida regulación matrimonial y estrictos requisitos para decretar la validez del contrato por el que una persona libre se vinculaba a otra como adscripticius.

\section{BIBLIOGRAFÍA}

BraVo, GonZalo. "El estatuto sociopolítico del colono en la génesis de la sociedad bajoimperial", Memorias de Historia Antigua, n. ${ }^{\circ} 2$, 1978, pp. 59-70.

BRAVO, GonZaLO. El colonato bajoimperial, Madrid: Akal, 1991.

BROSZ, R. "Les changements sémantiques du mot 'colonus' dans le sources du droit Romain", Annales Universitatis Scientarum Budapestinensis, 1959, pp. 39-55.

CarRIÉ, JeAn-Michel. "Le colonat du Bas-Empire: un myhte historiographique?", Opus, I.2, 1982, pp. 351-370.

CarriÉ, J. M. "Un roman des origines: Les généalogies du colonat du Bas-Empire", Opus, II.1, 1983, pp. 205-251.

Collinet, Paul. "Le colonat dans l'Empire Romain", Recueil de la Société Jean Bodin, Bruxelles, 1937, pp. 85-122.

CUENA BOY, FranCisCo. "Yanaconazgo y derecho romano: ¿una conjunción extravagante?", Revista de Estudios Histórico Jurídicos, Valparaíso, n. ${ }^{\circ}, 28$, 2006, pp. 401-424.

CUENA BOY, FRANCISCO. "Causa originis': Normas de procedimiento sobre la reclamación de colonos o curiales evadidos de su condición", Revista de Estudios HistóricoJurídicos, n. ${ }^{\circ}$ XXXIV, Valparaíso, 2012, pp. 55-89.

Humbert, Gustave, s. v. "colonus", Dictionnaire des Antiquités Grecques et Romaines (Daremberg, Saglio), 1.2, París, 1877, p. 1322.

De Dominicis, M. Antonio. "I coloni adscripticii nella legislazione di Giustiniano", Studi Betti, III, Milano, 1962, pp. 85-99. 
De NeEve, P.W. "Colon et colon partiaire", Mnemosyne, 37, 1984, pp. 125-142.

De Martino, Francesco. "Il colonato fra economia e diritto", AA.VV., Storia di Roma (dirs. A. Momigliano y A. Schiavone), III.1, Torino, 1989, pp. 789-822.

De Martino, Francesco. "Coloni in Italia", Labeo, I, 1995, pp. 35-65.

EIBACH, DiETHER. Untersucbungen zu spätantiken kolonat der kaiserlichen Gesetzgebung unter besonderer Berïcksichtigung der Terminologie, Cologne: Diss. Köln, 1977.

ERnout, A, Meillet, A. s. v. "colonus", Dictionnaire étymologique de la langue latine. Histoire des mots, $4 .^{\text {a }}$ ed., París, 1967, p. 132.

Fatás, Guillermo, Marco, Francisco. "Consideraciones sobre el colonato", Memorias de Historia Antigua, n. ${ }^{\circ} 2,1978$, pp. 181 ss.

Fernández de Buján, Antonio. Derecho Privado Romano. 8. ${ }^{a}$ ed.. Madrid: Iustel, 2015.

FUENTESECA, MARGARITA. "El colonus y el impuesto territorial", RIDROM, n. ${ }^{\circ} 3,2012$, pp. $28-103$.

Fustel de Coulanges, Denis. Le colonat romain, París: Arno Press, 1884.

Gascou, JEAN. "Les grands domaines, la cité et l'État en Égypte byzantine", Travaux et Mémoires Byz., 9, 1985, pp. 1-90.

GANSHOF, FRAnÇOIS. "Le statut personnel du colon au Bas-Empire. Observations en marge d'une théorie nouvelle", L'Antiquité Classique, 14, 1945, pp. 261-277.

Giliberti, Giuseppe. Servi della terra. Richerche per una storia del colonato, Torino: Giappichelli, 1998.

Goffart, W. Caput and Colonate. Towards a History of Late Roman Taxation, Toronto: University of Toronto Press, 1974.

GONZÁlez BlAnCO, ANTONIO. "Bibliografía sobre el colonado romano y sus problemas", Memorias de Historia Antigua, n. ${ }^{\circ}$ 2, 1979, pp. 229-237.

GonZÁlez Bravo, Antonio. "La condición de los colonos en la trama de la sociedad bajoimperial (según S. Juan Crisóstomo y la Historia Augusta)", Memorias de Historia Antigua, II, Actas del Coloquio 1978, Colonato y otras formas de dependencia no esclavista, Universidad de Oviedo, 1978, pp. 81-92.

Grey, C. "Contextualizing Colonatus: The Origo of the Late Roman Empire", Journal Roman Studies, n. ${ }^{\circ}$ 97, 2007, pp. 155-175. 
Jones, Arnold H.M. "El colonato romano", Estudios sobre Historia Antigua, Madrid, 1981, pp. 315-316.

Kolendo, JerZy. Le colonat en Afrique sous le Haut-Empire, Paris: Les Belles Lettres, 1976.

LÓPEZ Huguet, María LuISA. Régimen jurídico del domicilio en derecho romano, Madrid: Dykinson, 2008.

MARCONE, ARnAldo. Il colonato tardoantico nella storiografia moderna, Como: New Press, 1988.

MARCONE, ARNALDO. Storia dell'agricoltura romana, Roma: Nuova Italia Scientifica, 1997.

Marín García, María Teresa y José Antonio Martínez Vela, "Claves para el estudio del colonato romano", III Congreso Iberoamericano de Derecho Romano, León: Universidad de León, 1998, pp. 237-247.

Rosafio, PAsquale. "Coloni imperiali e coloni privati nella legislazione del quarto secolo", Atti dell'Accademia Romanistica Costantiniana. X Convegno Internazionale in onore di Arnaldo Biscardi, Perugia, 1991, pp. 447-459.

Rosafio, Pasquale. Studi sul colonato, Bari: Edipuglia, 2002.

RostovtzefF, M., s. v. "Kolonat", Handwörterbuch der Staatswissenschaften, V, 1910, pp. 919-920.

Saumagne, CH. "Du role de 'l'origo' et du 'census' dans la formation du colonat romain", Bizantion, 12, 1937, pp. 487-581.

Segré, Angelo. "The Byzantine Colonate", Traditio, n. o 5, 1947, pp. 103-133.

SIRKS BOUDEWIJN. "Reconsidering the Roman Colonate", ZSS, 110, 1993, pp. 331-369. 